\title{
The cumulative duration of bispectral index less than 40 concurrent with hypotension is associated with 90 -day postoperative mortality: a retrospective study
}

Soohyuk Yoon', Seokha Yoo', Min Hur², Sun-Kyung Park', Hyung-Chul Lee', Chul-Woo Jung ${ }^{1}$, Jae-Hyon Bahk ${ }^{1}$ and Jin-Tae Kim ${ }^{1 *}$ (D)

\begin{abstract}
Background: The relationship between intraoperative low bispectral index (BIS) values and poor clinical outcomes has been controversial. Intraoperative hypotension is associated with postoperative complication. The purpose of this study was to investigate the influence of intraoperative low BIS values and hypotension on postoperative mortality in patients undergoing major abdominal surgery.
\end{abstract}

Methods: This retrospective study analyzed 1862 cases of general anesthesia. We collected the cumulative time of BIS values below 20 and 40 as well as electroencephalographic suppression and documented the incidences in which these states were maintained for at least 5 min. Durations of intraoperative mean arterial pressures (MAP) less than $50 \mathrm{mmHg}$ were also recorded. Multivariable logistic regression was used to evaluate the association between suspected risk factors and postoperative mortality.

Results: Ninety-day mortality and 180-day mortality were 1.5 and 3.2\% respectively. The cumulative time in minutes for BIS values falling below 40 coupled with MAP falling below $50 \mathrm{mmHg}$ was associated with 90-day mortality (odds ratio, 1.26; 95\% confidence interval, 1.04-1.53; $P=.019$ ). We found no association between BIS related values and 180-day mortality.

Conclusions: The cumulative duration of BIS values less than 40 concurrent with MAP less than $50 \mathrm{mmHg}$ was associated with 90-day postoperative mortality, not 180-day postoperative mortality.

Keywords: Bispectral index, Intraoperative hypotension, Postoperative mortality, Major abdominal surgery

\section{Background}

Monitoring anesthesia depth is essential for providing optimal anesthesia as it enables the maintenance of adequate anesthesia level [1]. The bispectral index (BIS) monitor can reduce the risk of intraoperative awareness as well as

\footnotetext{
* Correspondence: jintae73@gmail.com

${ }^{1}$ Department of Anesthesiology and Pain Medicine, Seoul National University College of Medicine, Seoul National University Hospital, 101 Daehak-ro, Jongno-gu, Seoul 03080, Republic of Korea

Full list of author information is available at the end of the article
}

facilitate faster recovery after general anesthesia by enabling the anesthesiologists to appropriately adjust the anesthetic dose [2, 3]. Recently, there has been a growing interest in how the depth of anesthesia monitored using BIS affects postoperative outcomes.

Several studies have suggested an association between low BIS value $(<40$ or 45$)$ and postoperative mortality [4-6]. However, data on a definite relationship between these remain inconclusive considering other studies [7, 8]. Sesller and colleagues first proposed that the low

(c) The Author(s). 2020 Open Access This article is licensed under a Creative Commons Attribution 4.0 International License, which permits use, sharing, adaptation, distribution and reproduction in any medium or format, as long as you give appropriate credit to the original author(s) and the source, provide a link to the Creative Commons licence, and indicate if changes were made. The images or other third party material in this article are included in the article's Creative Commons licence, unless indicated otherwise in a credit line to the material. If material is not included in the article's Creative Commons licence and your intended use is not permitted by statutory regulation or exceeds the permitted use, you will need to obtain permission directly from the copyright holder. To view a copy of this licence, visit http://creativecommons.org/licenses/by/4.0/. The Creative Commons Public Domain Dedication waiver (http://creativecommons.org/publicdomain/zero/1.0/) applies to the data made available in this article, unless otherwise stated in a credit line to the data. 
mean arterial pressure (MAP) during low minimum alveolar concentration (MAC) of inhalation anesthetics combined with low BIS value was a predictor of mortality, [9] followed by conflicting results [10, 11]. Another study showed an association between intraoperative electroencephalographic (EEG) suppression and postoperative mortality, only when EEG suppression was concomitant with low MAP (<55 mmHg) [12].

Furthermore, other studies revealed that prolonged concurrent double low time of BIS and MAP was associated with higher mortality. Maheshwari and colleagues focused on 30-day mortality after cardiac surgery and they set the cutoff value of double low by calculating time-weighted average of BIS and MAP, which were $<43$ and $<75 \mathrm{mmHg}$ respectively [13]. Meanwhile, other prospective study used the thresholds of $75 \mathrm{mmHg}$ for MAP and 45 for BIS and involved all surgical specialties of noncardiac surgery to investigate 90-day mortality [14].

Intraoperative low BIS values and hypotension can have an influence on postoperative mortality. However, it remains unclear whether low BIS values concomitant with hypotension can affect intermediate to long term mortality considering the type of surgery and definition of double low $[12,13]$. The relationship between the cumulative duration of low BIS value or EEG suppression and poor clinical outcomes also remains to be determined. The primary goal of this study was to determine whether intraoperative low BIS value $(<40$ or 20$)$, EEG suppression and low BIS value coupled with hypotension are associated with postoperative mortality in patients who underwent major abdominal surgery.

\section{Methods}

This manuscript adheres to the applicable STROBE (Strengthening the Reporting of Observational Studies in Epidemiology) guidelines.

\section{Patient population}

The intraoperative data used in this study were obtained from the "Registry Construction of Intraoperative Vital Signs and Clinical Information in Surgical Patients" study (H1408-101-605, NCT02914444), which was designed to store intraoperative time-synchronized data from multiple anesthesia devices including patient monitors, anesthesia machines, BIS monitors, cardiac output monitors, and targetcontrolled infusion pumps by use of the 'Vital Recorder' (VitalDB team, Seoul, Korea) program. Using this registry, we could obtain complete intraoperative data (BIS-derived values, MAPs, and anesthetic concentrations).

Data collected for this study came from adult patients who underwent surgeries at Seoul National University Hospital between August 2016 and June 2017 under general anesthesia with BIS monitoring (BIS Vista, Covidien, Dublin, Ireland). The surgical procedures performed included abdominal surgeries on the gastrointestinal tract, liver, biliary tract, and pancreas. Data from the following cases were excluded: patients under 18 years old, cases with missing BIS value and MAP data more than $60 \mathrm{~s}$, anesthesia times of less than $60 \mathrm{~min}$, incomplete data on mortality, and reoperations during the period of analysis.

\section{Data collection}

Vital sign data and clinical information pertaining to the cases were retrospectively analyzed. The data included patient's diagnosis, age, sex, height, weight, type of operation, type and duration of anesthesia, propofol (Fresofol MCT inj 2\%, Fresenius Kabi) concentration, MAC of volatile anesthetics, intraoperative BIS values, and arterial blood pressure. When MAP was less than $20 \mathrm{mmHg}$ or greater than $200 \mathrm{mmHg}$, and when BIS was 0, these values were regarded as missing values.

To investigate the relationship between the duration of low BIS value maintenance and postoperative outcomes, we estimated the cumulative time in which BIS values were less than 20 or 40 and designated these as "bis20 dur" and "bis40_dur" respectively. To calculate total time of EEG suppression, designated as "eegsup_dur", we used a suppression ratio. The suppression ratio is the percentage of time over the last 63-s period in which the signal is considered to be in the suppressed state. As an example, a suppression ratio of 40 would mean "isoelectric over $40 \%$ of the last 63 seconds". After documenting suppression ratios at every second during anesthesia, we estimated the total time during which a patient's EEG was suppressed by summing each case's fractional suppression ratios applying a method used previously [12]. Lastly, we divided the sum by 60 to convert seconds to minutes and then by 100 to make percentages absolute numbers. To investigate the effects of short duration of brain suppression on clinical outcomes, we looked at the incidence in which cumulative time of BIS values less than 20 or 40 and EEG suppression lasted more than 5 min (bis20_5min, bis40_5min, and eegsup_5min respectively). To evaluate the influence of hypotension, we estimated the total time that MAP was lower than 50 $\mathrm{mmHg}$ (map50_dur) considering previous study [15]. We also calculated the cumulative time that MAP was less than $50 \mathrm{mmHg}$ and BIS values were less than 20 or 40 simultaneously (bis20map50_dur, bis40map50_dur).

Potential clinical risk factors of postoperative mortality and delirium were determined in priori by clinical relevance or significance following a previous study [12]. We reviewed electronic medical records to retrieve the variables related to postoperative mortality and delirium. They included American Society of Anesthesiologists (ASA) physical status, past medical histories including the presence of aortic stenosis, congestive heart failure, coronary artery disease, hypertension, peripheral 
vascular occlusive disease, dysrhythmia, chronic obstructive pulmonary disease, pulmonary hypertension, stroke, malignancy, diabetes mellitus, sleep apnea, social history of smoking and drinking, and preoperative laboratory test results including hemoglobin $(\mathrm{g} / \mathrm{dL})$ and albumin $(\mathrm{g} / \mathrm{dL})$.

\section{Postoperative outcome}

Mortality data were obtained from the Korean Ministry of the Interior and Safety using the resident registration number for each patient in February 2018. In this process, every piece of personal information collected was encrypted so as to maintain patient confidentiality. Mortality data were divided into 90-day postoperative mortality and 180-day mortality to compare early-tointermediate term and intermediate-to-long term outcomes [16].

\section{Statistical analysis}

Normality of continuous variables was verified with Kolmogorov-Smirnov test. In the univariable analysis, each variable of the data was analyzed by binary logistic regression in 'enter' method as an independent variable of postoperative mortality. Variables yielding $P$-values under 0.2 in the univariable analysis were selected as potential risk factors for multivariable analysis.

After the univariable analysis, we confirmed multicollinearity by calculating VIF (variance inflation factor) values of the potential risk factors and used value of 10 as the VIF threshold. Considering the multicollinearity, we used 2-step multivariable analysis to select more reliable variables. In the first step, among the selected risk factors from univariable analysis, variable considered to have a multicollinearity was separately included in binary logistic regression with 'enter' method after excluding possibly related variables. In this step, we removed potential BIS or MAP derived variables not yielding $P$-values under 0.05 . In second step, selected BIS or MAP derived variables in first step and other potential risk factors not related to BIS or MAP in univariable analysis were included in final multivariable logistic regression analysis in 'backward LR' method. Variables remaining in the final logistic regression model were regarded as significant risk factors. The Hosmer-Lemeshow goodness-of-fit test was used to compare the estimate with the observed likelihood of outcomes.

To compare anesthetic concentration and double low duration between patients with and without adverse outcome, we used Student $t$ test or Mann-Whitney U test, as appropriate. All statistical analyses were performed using SPSS software version 23 (IBM Corp., Armonk, New York, USA) and RStudio software version 1.2 (R studio, Boston, Massachusetts, USA).

\section{Results}

The total number of cases during the period in the $\mathrm{H}$ 1408-101-605 registry were 6423 and we included 2562 cases according to surgical procedure. After applying exclusion criteria, a total of 1862 records were included. Causes of exclusion are described in a CONSORT flowchart (Fig. 1).

In the study cohort, 90-day postoperative mortality and 180-day postoperative mortality were 1.5 and 3.2\%, respectively. Demographics and basic patient characteristics, specifics of the operation and anesthesia, numeric details of the BIS-derived variables and other covariates are summarized with their mean and standard deviation (SD) or number with percentage (\%) in Table 1.

\section{0-day mortality}

In univariable analysis, age, male sex, dysrhythmia, chronic obstructive pulmonary disease, pulmonary hypertension, malignancy, diabetes, ASA classification, hemoglobin levels, albumin levels, map50_dur and bis40map50_dur were found to be potential risk factors for 90-day mortality. After the first step of multivariable analysis, only bis40map50_dur was statistically significant $(P=.046)$ among BIS or MAP derived variables. In the final multivariable analysis, male sex, dysrhythmia, hemoglobin levels, albumin levels, and bis40map50_dur [odds ratio (OR), 1.26; $P=.019$ ] were associated with 90-day mortality (Table 2). Hosmer and Lemeshow goodness of fit test is not significant at 5\% $(P=.927)$.

There were no significant differences of mean propofol concentration [2.84 $\mu \mathrm{g} / \mathrm{mL}$ vs. $3.09 \mu \mathrm{g} / \mathrm{mL}$ respectively; $95 \%$ confidence interval $(\mathrm{CI})-0.67$ to $1.16 ; P=.597$ ] and MAC of volatile anesthetics $(0.91$ vol\% vs. 0.96 vol\% respectively; $P=.292$ ) between patients with and without 90-day mortality.

\section{0-day mortality}

In univariable analysis, age, male sex, body mass index, category of operation, dysrhythmia, pulmonary hypertension, malignancy, diabetes, ASA classification, hemoglobin levels, albumin levels and bis40map50_dur were found to be potential risk factors for 180-day mortality. In multivariable analysis, category of surgical procedures, dysrhythmia, malignancy, ASA classification, hemoglobin levels and albumin levels were found to significantly predict 180-day mortality. No BIS or MAP derived variables had any significant relationship with 180-day mortality (Table 3). Hosmer and Lemeshow goodness of fit test is not significant at $5 \%(P=.326)$.

There were no significant differences of mean propofol dose $(2.94 \mu \mathrm{g} / \mathrm{mL}$ vs. $3.09 \mu \mathrm{g} / \mathrm{mL}$ respectively; $95 \% \mathrm{CI}-$ 0.46 to $0.75 ; P=.646)$ and MAC of volatile anesthetics (0.92 vol\% vs. 0.96 vol\% respectively; $95 \% \mathrm{CI}-0.01$ to 


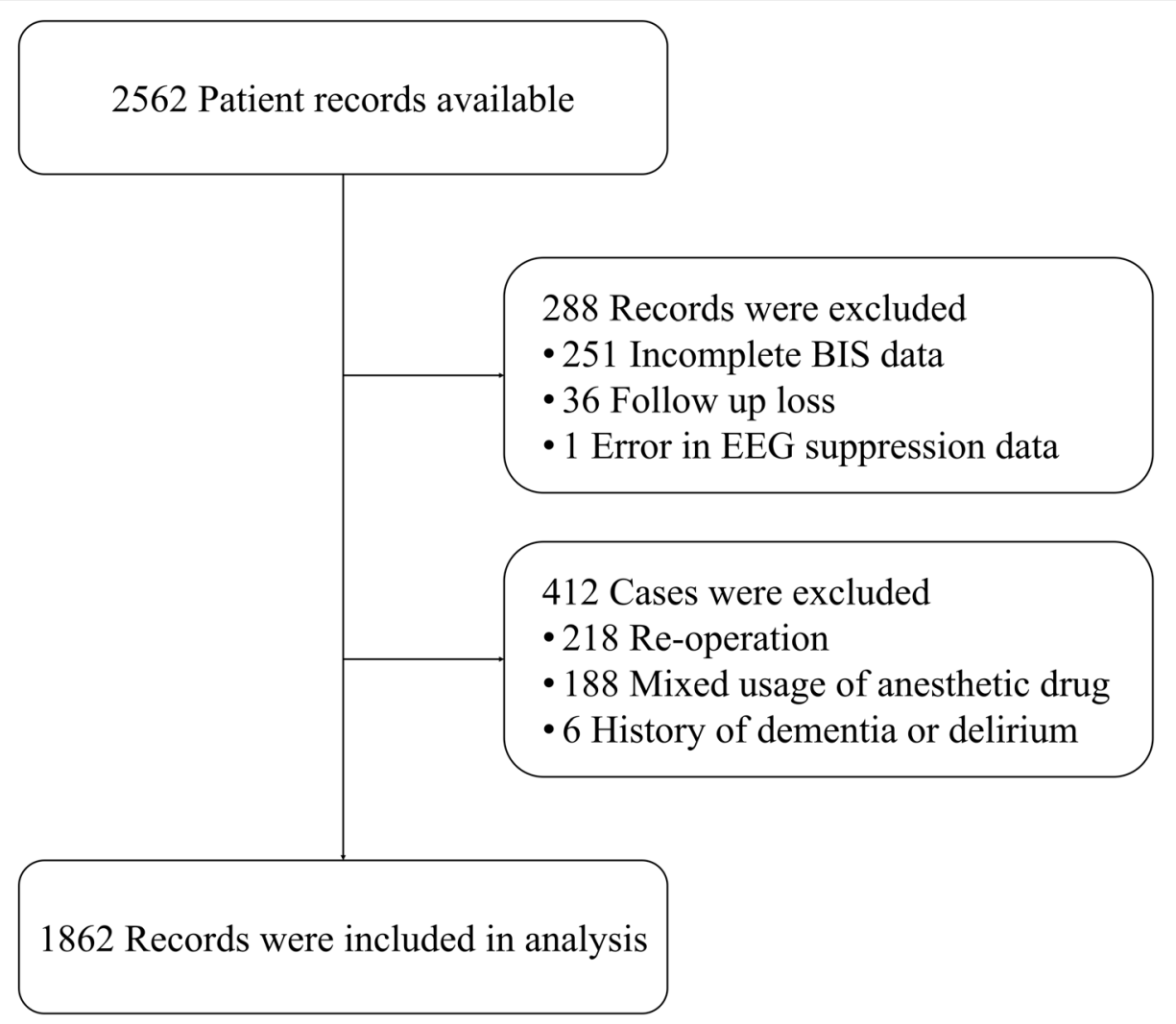

Fig. 1 CONSORT flowchart: only remained cases after exlcusion were included for statistical analysis. BIS, bispectral index; EEG, electroencephalogram

$0.09 ; P=.115)$ between patients with and without 180 day mortality.

\section{Subgroup analysis}

There was no significant difference of mean propofol concentration $(3.20 \mu \mathrm{g} / \mathrm{mL}$ vs. $3.04 \mu \mathrm{g} / \mathrm{mL}$ respectively; 95\% CI -0.61 to $0.29 ; P=.480$ ) between patients who presented and who didn't present double low (BIS $<40$ and MAP < 50) among the total intravenous anesthesia (TIVA) cases. On the other hand, MAC of volatile anesthetics was higher in the patients who presented double low than who didn't present double low (0.97 vol\% vs. $0.95 \mathrm{~V} \%$ respectively; $95 \%$ CI 0.01 to $0.41 ; P=.010$ ) among the inhalation anesthesia cases.

Of the 659 patients who presented double low, ten patients were died in postoperative 90-day. Their mean duration of double low were $3.16 \mathrm{~min}$ (SD 4.57), while the mean duration of double low were $0.91 \mathrm{~min}$ (SD 1.22) in patients without 90-day mortality. There was significant difference of double low duration between these patients $(P=.020)$.

\section{Discussion}

The major finding of this study was that the duration of BIS values below 40 coupled with MAP less than 50 $\mathrm{mmHg}$ was associated with 90-day postoperative mortality, not 180-day postoperative mortality. This suggests that excessive anesthetic-induced brain suppression as well as intraoperative hypotension may be associated with adverse postoperative outcome.

Several early studies proposed statistical relationship between low BIS value ( $<40$ or 45$)$ and postoperative mortality [4-6]. However, the cumulative duration of BIS value less than 40 or 20, and EEG suppression alone were not related to postoperative mortality in this study, consistent with previous further observational studies, randomized controlled trial, and meta-analysis [7, 9, 12, $17,18]$. In contrast, other previous studies showed the association between postoperative mortality and 'double low' of BIS and MAP, [9, 12-14] similar to our results. These findings may imply that it is not possible to predict mortality and adverse outcomes by excessive suppression alone, but only with combined hypotension.

Two meta-analyses proposed relationship between low BIS value alone and 90-day or 1 - year postoperative mortality, not 30-day postoperative mortality [19, 20]. On the other hand, other previous studies reported that double low was associated with 30-day postoperative mortality $[9,13]$ or 90 -day postoperative mortality [12, 14]. This finding suggests that intraoperative low BIS values and blood pressure seem to be related to early-tointermediate postoperative mortality and not to 
Table 1 Characteristics of cohort

\begin{tabular}{|c|c|}
\hline Variables & All patients $(r$ \\
\hline Age (year) & $63.1(19-91)$ \\
\hline Male sex & $1088(58.4 \%)$ \\
\hline Body mass index $\left(\mathrm{kg} / \mathrm{m}^{2}\right)$ & $23.4(3.5)$ \\
\hline \multicolumn{2}{|l|}{ Category of surgical procedures } \\
\hline Stomach & $492(26.4 \%)$ \\
\hline Colorectal & $719(38.6 \%)$ \\
\hline Hepatic & $154(8.3 \%)$ \\
\hline Biliary-pancreas & $497(26.7 \%)$ \\
\hline \multicolumn{2}{|l|}{ Type of anesthesia } \\
\hline Total intravenous anesthesia & $865(46.5 \%)$ \\
\hline Volatile agent & $997(53.5 \%)$ \\
\hline Duration of anesthesia (min) & $196.6(104.4)$ \\
\hline \multicolumn{2}{|l|}{ BIS derived variables } \\
\hline bis40_dur (min) & $70.5(73.2)$ \\
\hline bis40_5min & $1701(91.4 \%)$ \\
\hline bis20_dur (min) & $0.5(4.2)$ \\
\hline bis20_5min & $35(1.9 \%)$ \\
\hline eegsup_dur (min) & $1.6(6.6)$ \\
\hline eegsup_5min & $134(7.2 \%)$ \\
\hline bis40map50_dur (min) & $0.34(0.92)$ \\
\hline bis20map50_dur (min) & $0.01(0.11)$ \\
\hline map50_dur (min) & $0.8(1.7)$ \\
\hline \multicolumn{2}{|l|}{ Past medical history } \\
\hline Aortic stenosis & $10(0.5 \%)$ \\
\hline Congestive heart failure & $6(0.3 \%)$ \\
\hline Coronary artery disease & $98(5.3 \%)$ \\
\hline Hypertension & $706(37.9 \%)$ \\
\hline Peripheral vascular occlusive disease & $6(0.3 \%)$ \\
\hline Dysrhythmia & $61(3.3 \%)$ \\
\hline Chronic obstructive pulmonary disease & $46(2.5 \%)$ \\
\hline Pulmonary hypertension & $7(0.4 \%)$ \\
\hline Stroke & $70(3.8 \%)$ \\
\hline Malignancy & $1368(73.5 \%)$ \\
\hline Diabetes & $398(21.4 \%)$ \\
\hline Sleep apnea & $3(0.2 \%)$ \\
\hline \multicolumn{2}{|l|}{ Social history } \\
\hline Current smoker & $255(13.7 \%)$ \\
\hline Regular alcohol ingestion & $449(24.1 \%)$ \\
\hline \multicolumn{2}{|l|}{ ASA classification } \\
\hline । & $456(24.5 \%)$ \\
\hline$\|$ & $1181(63.4 \%)$ \\
\hline$\| I$ & $221(11.9 \%)$ \\
\hline IV & $4(0.2 \%)$ \\
\hline
\end{tabular}

Table 1 Characteristics of cohort (Continued)

\begin{tabular}{|c|c|}
\hline Variables & All patients $(n=1862)$ \\
\hline \multicolumn{2}{|l|}{ Laboratory tests } \\
\hline Hemoglobin (g/dL) & $10.5(3.7)$ \\
\hline Albumin (g/dL) & $3.7(1.0)$ \\
\hline \multicolumn{2}{|c|}{$\begin{array}{l}\text { Continuous variables are presented with their mean (standard deviation) } \\
\text { except age [mean (range)], and categorical variables are presented with their } \\
\text { number (percentage) } \\
\text { Abbreviations: BIS Bispectral index; bis } 40 \text { ddur, cumulative time in which BIS }<40 \text {; } \\
\text { bis } 40 \text { mmin, incidence in which cumulative time of BIS }<40 \text { lasted }>5 \text { min; bis } 20 \text { dur, } \\
\text { cumulative time in which BIS }<20 ; \text { bis } 20 \_5 \text { min, incidence in which cumulative time of } \\
\text { BIS }<20 \text { lasted }>5 \text { min; EEG Electroencephalogram; eegsup_dur, cumulative time in } \\
\text { which patient's EEG was suppressed; eegsup_5min, incidence in which cumulative } \\
\text { time of EEG suppression lasted }>5 \text { min; MAP Mean arterial pressure; bis } 40 \text { map50_dur, } \\
\text { cumulative time that BIS }<40 \text { and MAP }<50 \mathrm{mmHg} \text { simultaneously; bis } 20 \text { map50_dur, } \\
\text { cumulative time that BIS }<20 \text { and MAP }<50 \mathrm{mmHg} \text { simultaneously; map50_dur, } \\
\text { cumulative time that MAP }<50 \mathrm{mmHg} \text {; ASA The American Society of Anesthesiologists } \\
\text { physical status }\end{array}$} \\
\hline
\end{tabular}

intermediate-to-long term mortality. The sequelae of intraoperative events and excessive anesthesia can lead to early postoperative complications which is associated with early-to-intermediate mortality, but the effect seems to be time-limited.

In this study, mean propofol concentrations were not statistically different between patients with or without double low among TIVA cases. Therefore, patients who presented double low may have had higher anesthetic vulnerability, which means that some patients are prone to show lower BIS values and hypotension in similar anesthetic dosage, followed by postoperative adverse outcomes. On the other hand, in inhalational anesthesia, mean MAC of volatile anesthetics was higher in the patients with double low. In this respect, excessive anesthesia also can be a cause of double low and, furthermore, postoperative mortality. In addition, as Charier and colleagues mentioned in their review, opioid administration can affect both hypnosis and arterial hypotension, [21] so that it would be more pragmatic to take into account the nociception-analgesia balance as well. Further research is needed to investigate the difference in anesthetic vulnerability according to the type of anesthesia or opioid administration. Nevertheless, BIS monitoring and titration of anesthetics can help avoid unnecessarily deep anesthesia and possible neurotoxic effects in vulnerable patients, [22] yet there is still a lack of evidence by prospective studies [14] whether avoiding 'double low' state can improve postoperative outcomes.

The Vital Recorder program, which was used to collect BIS values, suppression ratios and MAP data in this study, is an automatic recording device for obtaining high-resolution time-synchronized physiological data from multiple anesthesia devices [23]. With this software we could obtain stored digitalized data for every patient, as well as accurately compute the independent variables related to BIS and MAP. Furthermore, intraoperative target site propofol concentrations in TIVA and MAC of 
Table 2 Association between variables and 90-day postoperative mortality

\begin{tabular}{|c|c|c|c|c|c|c|}
\hline \multirow[t]{2}{*}{ Variables } & \multicolumn{3}{|c|}{ Univariable association } & \multicolumn{3}{|c|}{ Multivariable association } \\
\hline & $\overline{\mathrm{OR}}$ & $95 \% \mathrm{Cl}$ & $P$-value ${ }^{a}$ & $\overline{\mathrm{OR}}$ & $95 \% \mathrm{Cl}$ & $P$-value ${ }^{b}$ \\
\hline Age (year) & 1.02 & $0.99-1.06$ & .146 & & & .438 \\
\hline Male sex ${ }^{b}$ & 2.64 & $1.07-6.55$ & .036 & 3.22 & $1.24-8.36$ & .017 \\
\hline Body mass index $\left(\mathrm{kg} / \mathrm{m}^{2}\right)$ & 0.97 & $0.87-1.08$ & .539 & & & \\
\hline Category of surgery (vs. Stomach) & & & .239 & & & \\
\hline Colorectal & 1.84 & $0.72-4.75$ & .205 & & & \\
\hline Hepatic & 1.07 & $0.21-5.34$ & .938 & & & \\
\hline Biliary-pancreas & 0.66 & $0.18-2.34$ & .518 & & & \\
\hline Volatile agent compared with TIVA & 1.00 & $0.47-2.12$ & .998 & & & \\
\hline Duration of anesthesia (min) & 1.00 & $0.99-1.00$ & .774 & & & \\
\hline bis40_dur (min) & 1.00 & $0.99-1.01$ & .876 & & & \\
\hline bis40_5min & 2.58 & $0.35-19.12$ & .353 & & & \\
\hline bis20_dur (min) & 0.57 & $0.14-2.33$ & .432 & & & \\
\hline bis20_5min & $<0.01$ & & .998 & & & \\
\hline eegsup_dur (min) & 0.95 & $0.82-1.10$ & .483 & & & \\
\hline eegsup_5min & 0.47 & $0.06-3.51$ & .465 & & & \\
\hline bis40map50_dur ${ }^{b}$ (min) & 1.38 & $1.16-1.65$ & $<.001$ & 1.26 & $1.04-1.53$ & .019 \\
\hline bis20map50_dur (min) & 1.89 & $0.44-8.08$ & .393 & & & \\
\hline map50_dur* (min) & 1.12 & $1.00-1.26$ & .057 & & & \\
\hline \multicolumn{7}{|l|}{ Past medical history } \\
\hline Aortic stenosis & $<0.01$ & & .999 & & & \\
\hline Congestive heart failure & $<0.01$ & & .999 & & & \\
\hline Coronary artery disease & 1.39 & $0.33-5.95$ & .655 & & & \\
\hline Hypertension & 0.91 & $0.42-1.98$ & .809 & & & \\
\hline Peripheral vascular occlusive disease & $<0.01$ & & .999 & & & \\
\hline Dysrhythmia $^{b}$ & 5.20 & $1.75-15.47$ & .003 & 4.26 & $1.24-14.59$ & .021 \\
\hline Chronic obstructive pulmonary disease & 3.13 & $0.72-13.60$ & .128 & & & .805 \\
\hline Pulmonary hypertension & 11.28 & $1.31-96.95$ & .027 & & & .200 \\
\hline Stroke & $<0.01$ & & .997 & & & \\
\hline Malignancy & 4.77 & $1.13-20.16$ & .034 & & & .219 \\
\hline Diabetes & 2.07 & $0.95-4.52$ & .068 & & & .618 \\
\hline Sleep apnea & $<0.01$ & & .999 & & & \\
\hline Current smoker & 1.74 & $0.70-4.32$ & .236 & & & \\
\hline Regular alcohol ingestion & 0.86 & $0.35-2.13$ & .738 & & & \\
\hline ASA (compared with ASA I) & & & .012 & & & .539 \\
\hline$\|$ & 7.04 & $0.94-52.91$ & .058 & & & .986 \\
\hline III & 19.32 & $2.43-153.44$ & .005 & & & .335 \\
\hline IV & $<0.01$ & & .999 & & & .795 \\
\hline Hemoglobin ${ }^{\mathrm{b}}$ level (g/dL) & 0.56 & $0.46-0.69$ & $<.001$ & 0.70 & $0.55-0.89$ & .004 \\
\hline Albumin ${ }^{b}$ level (g/dL) & 0.11 & $0.05-0.21$ & $<.001$ & 0.21 & $0.09-0.47$ & $<.001$ \\
\hline
\end{tabular}

${ }^{\mathrm{a}}$ After binary logistic regression in 'enter' method, variables yielding $P$-values under 0.2 were regarded to be potential risk factors. ${ }^{\mathrm{b}}$ In the final multivariable logistic regression analysis in 'backward LR' method, variables remaining in final model were regarded as significant risk factors. ${ }^{*}$ BIS or MAP derived variables not yielding $P$-values under 0.05 in the first step of multivariable analysis were excluded from final analysis

Abbreviations: OR Odds ratio; $\mathrm{Cl}$ Confidence interval; TIVA Total intravenous anesthesia; BIS Bispectral index; bis40 dur, cumulative time in which BIS < 40; bis40_5min, incidence in which cumulative time of BIS $<40$ lasted $>5$ min; bis20_dur, cumulative time in which BIS $<20$; bis20_5min, incidence in which cumulative time of BIS $<20$ lasted $>5$ min; EEG Electroencephalogram; eegsup_dur, cumulative time in which patient's EEG was suppressed; eegsup_5min, incidence in which cumulative time of EEG suppression lasted $>5$ min; MAP Mean arterial pressure; bis40map50_dur, cumulative time that BIS $<40$ and MAP $<50 \mathrm{mmHg}$ simultaneously; bis20map50_dur, cumulative time that BIS $<20$ and MAP $<50$ mmHg simultaneously; map50_dur, cumulative time that MAP $<50 \mathrm{mmHg}$; ASA The American Society of Anesthesiologists physical status 
Table 3 Association between variables and 180-day postoperative mortality

\begin{tabular}{|c|c|c|c|c|c|c|}
\hline \multirow[t]{2}{*}{ Variables } & \multicolumn{3}{|c|}{ Univariable association } & \multicolumn{3}{|c|}{ Multivariable association } \\
\hline & $\overline{\mathrm{OR}}$ & $95 \% \mathrm{Cl}$ & $\overline{P \text {-value }}{ }^{\mathrm{a}}$ & $\overline{\mathrm{OR}}$ & $95 \% \mathrm{Cl}$ & $P$-value ${ }^{\mathrm{b}}$ \\
\hline Age (year) & 1.03 & $1.01-1.06$ & .007 & & & .358 \\
\hline Male sex & 1.52 & $0.87-2.64$ & .141 & & & .243 \\
\hline Body mass index $\left(\mathrm{kg} / \mathrm{m}^{2}\right)$ & 0.86 & $0.79-9.34$ & $<.001$ & & & .230 \\
\hline Category of surgery ${ }^{b}$ (vs. Stomach) & & & .007 & & & .008 \\
\hline Colorectal $^{b}$ & 2.75 & $1.31-5.77$ & .008 & 3.34 & $1.51-7.39$ & .003 \\
\hline Hepatic & 2.18 & $0.76-6.21$ & .146 & 1.90 & $0.63-5.72$ & .260 \\
\hline Biliary-pancreas & 0.99 & $0.39-2.52$ & .983 & 1.23 & $0.46-3.30$ & .678 \\
\hline Volatile agent compared with TIVA & 0.83 & $0.50-1.50$ & .492 & & & \\
\hline Duration of anesthesia (min) & 1.00 & $0.99-1.00$ & .718 & & & \\
\hline bis40_dur (min) & 1.00 & $0.99-1.00$ & .876 & & & \\
\hline bis40_5min & 1.31 & $0.47-3.67$ & .605 & & & \\
\hline bis20_dur (min) & 0.99 & $0.90-1.09$ & .791 & & & \\
\hline bis20_5min & 1.88 & $0.44-8.04$ & .393 & & & \\
\hline eegsup_dur (min) & 1.01 & $0.97-1.04$ & .745 & & & \\
\hline eegsup_5min & 1.20 & $0.47-3.06$ & .700 & & & \\
\hline bis40map50_dur (min) & 1.22 & $1.03-1.44$ & .018 & & & .767 \\
\hline bis20map50_dur (min) & 1.45 & $0.33-6.25$ & .622 & & & \\
\hline map50_dur (min) & 1.05 & $0.93-1.18$ & .452 & & & \\
\hline \multicolumn{7}{|l|}{ Past medical history } \\
\hline Aortic stenosis & 3.44 & $0.43-27.58$ & .245 & & & \\
\hline Congestive heart failure & $<0.01$ & & .999 & & & \\
\hline Coronary artery disease & 0.62 & $0.15-2.59$ & .516 & & & \\
\hline Hypertension & 1.21 & $0.72-2.05$ & .474 & & & \\
\hline Peripheral vascular occlusive disease & $<0.01$ & & .999 & & & \\
\hline Dysrhythmia $^{b}$ & 4.36 & $1.89-10.04$ & .001 & 3.43 & $1.31-9.00$ & .012 \\
\hline Chronic obstructive pulmonary disease & 1.40 & $0.33-5.93$ & .645 & & & \\
\hline Pulmonary hypertension & 5.16 & $0.61-43.59$ & .131 & & & .563 \\
\hline Stroke & 0.43 & $0.06-3.17$ & .410 & & & \\
\hline Malignancy $^{\mathrm{b}}$ & 5.13 & $1.85-14.23$ & .002 & 3.08 & $1.05-9.03$ & .040 \\
\hline Diabetes & 2.09 & $1.21-3.61$ & .008 & & & .540 \\
\hline Sleep apnea & $<0.01$ & & .999 & & & \\
\hline Current smoker & 1.14 & $0.55-2.35$ & .723 & & & \\
\hline Regular alcohol ingestion & 0.71 & $0.37-1.39$ & .320 & & & \\
\hline ASA (compared with ASA I) & & & $<.001$ & & & .055 \\
\hline$\|$ & 7.55 & $1.81-31.41$ & .005 & 3.17 & $0.73-13.70$ & .122 \\
\hline\|\|$^{b}$ & 21.35 & $4.93-92.53$ & $<.001$ & 6.21 & $1.36-28.31$ & .018 \\
\hline IV & $<0.01$ & & .999 & 0.00 & 0.00 & .999 \\
\hline Hemoglobin ${ }^{\mathrm{b}}$ level (g/dL) & 0.56 & $0.48-0.65$ & $<.001$ & 0.79 & $0.66-0.95$ & .014 \\
\hline Albumin ${ }^{b}$ level (g/dL) & 0.11 & $0.07-0.18$ & $<.001$ & 0.18 & $0.10-0.32$ & .000 \\
\hline
\end{tabular}

${ }^{\mathrm{a}}$ After binary logistic regression in 'enter' method, variables yielding $P$-values under 0.2 were regarded to be potential risk factors. ${ }^{\mathrm{b}}$ In the final multivariable logistic regression analysis in 'backward LR' method, variables remaining in final model were regarded as significant risk factors Abbreviations: OR Odds ratio; CI Confidence interval; TIVA Total intravenous anesthesia; BIS Bispectral index; bis40_dur, cumulative time in which BIS < 40; bis40 5min, incidence in which cumulative time of BIS $<40$ lasted $>5 \mathrm{~min}$; bis 20 dur, cumulative time in which BIS $<20$; bis 20 min, incidence in which cumulative time of BIS < 20 lasted > 5 min; EEG Electroencephalogram; eegsup_dur, cumulative time in which patient's EEG was suppressed; eegsup_5min, incidence in which cumulative time of EEG suppression lasted $>5$ min; MAP Mean arterial pressure; bis40map50_dur, cumulative time that BIS < 40 and MAP < 50 mmHg simultaneously; bis20map50_dur, cumulative time that BIS $<20$ and MAP $<50$ mmHg simultaneously; map50_dur, cumulative time that MAP $<50 \mathrm{mmHg}$; ASA The American Society of Anesthesiologists physical status 
volatile agents in inhalational anesthesia were recorded in real time.

This study derived relationship between the cumulative duration of concurrent double low and postoperative mortality, especially focusing on the abdominal surgeries including gastrointestinal tract, liver, biliary tract, and pancreas surgeries. Other previous studies revealed comparable results on influence of low BIS and hypotension in other types of surgeries, $[13,14]$ and this study can support the results so far in respect of major abdominal surgery. Meanwhile, the cutoff value of MAP was $50 \mathrm{mmHg}$ in this study according to several definitions of clinically significant hypotension [12, 15, 24, 25]. Although it would be less conservative than the cutoff value of $75 \mathrm{mmHg}$, we tried to investigate narrower sense of definition of double low.

This study had several limitations. First, the incidence of postoperative mortality was relatively smaller than that in previous reports $[10,12,26]$. For a more accurate statistical analysis, a larger number of cases would be needed. Second, this study has limitation from the design of retrospective study. Data can be incomplete. Nevertheless, all intraoperative data were completely obtained using the 'Vital Recorder' program. Third, we included only patients receiving major abdominal surgeries to decrease other bias originated from different surgery and population. However, this may be another limitation for generalization of our results.

\section{Conclusions}

In conclusion, the cumulative duration of BIS values less than 40 coupled with MAP less than $50 \mathrm{mmHg}$ was associated with 90 -day postoperative mortality, not 180 day postoperative mortality.

\begin{abstract}
Abbreviations
BIS: Bispectral index; MAP: Mean arterial pressure; MAC: Minimal alveolar concentration; EEG: Electroencephalography; bis40_dur: Cumulative time in which BIS values were less than 40; bis40_5min: Incidence in which cumulative time of BIS values less than 40 lasted more than 5 min; bis20_dur: Cumulative time in which BIS values were less than 20; bis20_5min: Incidence in which cumulative time of BIS values less than 20 lasted more than 5 min; eegsup_dur: Cumulative time in which patient's EEG was suppressed; eegsup_5min: Incidence in which cumulative time of EEG suppression lasted more than 5 min; map50_dur: Cumulative time that MAP was less than $50 \mathrm{mmHg}$; bis40map50_dur: Cumulative time that BIS values were less than 40 and MAP was less than $50 \mathrm{mmHg}$ simultaneously; bis20map50_dur: Cumulative time that BIS values were less than 20 and MAP was less than $50 \mathrm{mmHg}$ simultaneously; ASA: American Society of Anesthesiologists; VIF: Variance inflation factor; TIVA: Total intravenous anesthesia
\end{abstract}

\section{Acknowledgements}

This work was supported by the Department of Anesthesiology and Pain Medicine, SNUH. The statistical analysis was done under the consultation of Medical Research Collaborating Center (MRCC) of SNUH.

\section{Authors' contributions}

CWJ and JTK designed the study. MH and HCL prepared study material and collected data. S-Yoo and SKP interpreted and statistically analyzed the data.
S-Yoon wrote first draft of the manuscript. JHB and JTK substantively revised the manuscript and corrected English expression. All authors read and approved the final version of the manuscript.

\section{Funding}

This study was supported by departmental funding only.

\section{Availability of data and materials}

All original datasets used and analyzed during the current study are available from the corresponding author on reasonable request.

\section{Ethics approval and consent to participate}

This study received approval from the Institutional Review Board (IRB) of Seoul National University Hospital (SNUH) in February 2018 (Approval number: H1801-031-913). The requirement of written informed consent was waived by the SNUH-IRB

\section{Consent for publication \\ Not applicable.}

\section{Competing interests}

The authors declare that they have no competing interests.

\section{Author details}

${ }^{1}$ Department of Anesthesiology and Pain Medicine, Seoul National University College of Medicine, Seoul National University Hospital, 101 Daehak-ro, Jongno-gu, Seoul 03080, Republic of Korea. ${ }^{2}$ Department of Anesthesiology and Pain Medicine, Ajou University Hospital, 164 World cup-ro,

Yeongtong-gu, Suwon-si, Gyeonggi-do 16499, Republic of Korea.

Received: 25 February 2020 Accepted: 9 August 2020

Published online: 14 August 2020

\section{References}

1. Das S, Ghosh S. Monitored anesthesia care: an overview. J Anaesthesiol Clin Pharmacol. 2015;31(1):27-9.

2. Gan TJ, Glass PS, Windsor A, Payne F, Rosow C, Sebel P, et al. Bispectral index monitoring allows faster emergence and improved recovery from propofol, alfentanil, and nitrous oxide anesthesia. BIS Utility Study Group Anesthesiology 1997;87(4):808-815.

3. Myles PS, Leslie K, McNeil J, Forbes A, Chan MT. Bispectral index monitoring to prevent awareness during anaesthesia: the B-aware randomised controlled trial. Lancet. 2004;363(9423):1757-63.

4. Monk TG, Saini V, Weldon BC, Sigl JC. Anesthetic management and oneyear mortality after noncardiac surgery. Anesth Analg. 2005;100(1):4-10.

5. Kertai MD, Pal N, Palanca BJ, Lin N, Searleman SA, Zhang L, et al. Association of perioperative risk factors and cumulative duration of low bispectral index with intermediate-term mortality after cardiac surgery in the B-unaware trial. Anesthesiology. 2010;112(5):1116-27.

6. Leslie K, Myles PS, Forbes A, Chan MT. The effect of bispectral index monitoring on long-term survival in the B-aware trial. Anesth Analg. 2010; 110(3):816-22

7. Kertai MD, Palanca BJ, Pal N, Burnside BA, Zhang L, Sadiq F, et al. Bispectral index monitoring, duration of bispectral index below 45 , patient risk factors, and intermediate-term mortality after noncardiac surgery in the B-unaware trial. Anesthesiology. 2011;114(3):545-56.

8. Leslie K, Short TG. Anesthetic depth and long-term survival: an update. Can J Anaesth. 2016:63(2):233-40

9. Sessler DI, Sigl JC, Kelley SD, Chamoun NG, Manberg PJ, Saager L, et al. Hospital stay and mortality are increased in patients having a "triple low" of low blood pressure, low bispectral index, and low minimum alveolar concentration of volatile anesthesia. Anesthesiology. 2012:116(6):1195-203.

10. Willingham MD, Karren E, Shanks AM, O'Connor MF, Jacobsohn E, Kheterpal $\mathrm{S}$, et al. Concurrence of intraoperative hypotension, low minimum alveolar concentration, and low Bispectral index is associated with postoperative death. Anesthesiology. 2015;123(4):775-85.

11. Kertai MD, White WD, Gan TJ. Cumulative duration of "triple low" state of low blood pressure, low bispectral index, and low minimum alveolar concentration of volatile anesthesia is not associated with increased mortality. Anesthesiology. 2014;121(1):18-28. 
12. Willingham M, Ben Abdallah A, Gradwohl S, Helsten D, Lin N, Villafranca A, et al. Association between intraoperative electroencephalographic suppression and postoperative mortality. Br J Anaesth. 2014;113(6):1001-8.

13. Maheshwari A, McCormick PJ, Sessler DI, Reich DL, You J, Mascha EJ, et al. Prolonged concurrent hypotension and low bispectral index ('double low') are associated with mortality, serious complications, and prolonged hospitalization after cardiac surgery. Br J Anaesth. 2017;119(1):40-9.

14. McCormick PJ, Levin MA, Lin HM, Sessler DI, Reich DL. Effectiveness of an electronic alert for hypotension and low Bispectral index on 90-day postoperative mortality: a prospective, randomized trial. Anesthesiology. 2016:125(6):1113-20.

15. Hirsch J, DePalma G, Tsai TT, Sands LP, Leung JM. Impact of intraoperative hypotension and blood pressure fluctuations on early postoperative delirium after non-cardiac surgery. Br J Anaesth. 2015;115(3):418-26.

16. Collins TC, Petersen NJ, Menke TJ, Souchek J, Foster W, Ashton CM. Shortterm, intermediate-term, and long-term mortality in patients hospitalized for stroke. J Clin Epidemiol. 2003:56(1):81-7.

17. Short TG, Campbell D, Frampton C, Chan MTV, Myles PS, Corcoran TB, et al. Anaesthetic depth and complications after major surgery: an international, randomised controlled trial. Lancet. 2019;394(10212):1907-14.

18. Vlisides PE, loannidis JPA, Avidan MS. Hypnotic depth and postoperative death: a Bayesian perspective and an independent discussion of a clinical trial. Br J Anaesth. 2019;122(4):421-7.

19. Liu YH, Qiu DJ, Jia L, Tan JT, Kang JM, Xie T, et al. Depth of anesthesia measured by bispectral index and postoperative mortality: a meta-analysis of observational studies. J Clin Anesth. 2019:56:119-25.

20. Zorrilla-Vaca A, Healy RJ, Wu CL, Grant MC. Relation between bispectral index measurements of anesthetic depth and postoperative mortality: a meta-analysis of observational studies. Can J Anaesth. 2017;64(6):597-607.

21. Charier D, Longrois D, Chapelle C, Salaun JP, Molliex S. Deep anaesthesia and postoperative death: is the matter resolved? Anaesth Crit Care Pain Med. 2020;39(1):21-3.

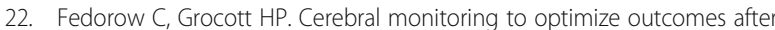
cardiac surgery. Curr Opin Anaesthesiol. 2010;23(1):89-94.

23. Lee HC, Jung CW. Vital recorder-a free research tool for automatic recording of high-resolution time-synchronised physiological data from multiple anaesthesia devices. Sci Rep. 2018;8(1):1527.

24. Monk TG, Bronsert MR, Henderson WG, Mangione MP, Sum-Ping ST, Bentt $\mathrm{DR}$, et al. Association between intraoperative hypotension and hypertension and 30-day postoperative mortality in noncardiac surgery. Anesthesiology. 2015;123(2):307-19.

25. Walsh M, Devereaux PJ, Garg AX, Kurz A, Turan A, Rodseth RN, et al. Relationship between intraoperative mean arterial pressure and clinical outcomes after noncardiac surgery: toward an empirical definition of hypotension. Anesthesiology. 2013;119(3):507-15.

26. Jakobson T, Karjagin J, Vipp L, Padar M, Parik AH, Starkopf L, et al. Postoperative complications and mortality after major gastrointestinal surgery. Medicina. 2014;50(2):111-7.

\section{Publisher's Note}

Springer Nature remains neutral with regard to jurisdictional claims in published maps and institutional affiliations.

Ready to submit your research? Choose BMC and benefit from:
- fast, convenient online submission
- thorough peer review by experienced researchers in your field
- rapid publication on acceptance
- support for research data, including large and complex data types
- gold Open Access which fosters wider collaboration and increased citations
- maximum visibility for your research: over 100M website views per year
At BMC, research is always in progress.
Learn more biomedcentral.com/submissions

